University of Nebraska - Lincoln

DigitalCommons@University of Nebraska - Lincoln

P. F. (Paul Frazer) Williams Publications

Electrical \& Computer Engineering, Department

December 1983

\title{
Photodetachment as a Control Mechanism for Diffuse Discharge Switches
}

Gerhard Schaefer

IEEE

P. F. Williams

University of Nebraska - Lincoln, pfw@moi.unl.edu

Karl H. Schoenbach

IEEE

John T. Moseley

University of Oregon, Eugene, OR

Follow this and additional works at: https://digitalcommons.unl.edu/elecengwilliams

Part of the Electrical and Computer Engineering Commons

Schaefer, Gerhard; Williams, P. F.; Schoenbach, Karl H.; and Moseley, John T., "Photodetachment as a Control Mechanism for Diffuse Discharge Switches" (1983). P. F. (Paul Frazer) Williams Publications. 14. https://digitalcommons.unl.edu/elecengwilliams/14

This Article is brought to you for free and open access by the Electrical \& Computer Engineering, Department of at DigitalCommons@University of Nebraska - Lincoln. It has been accepted for inclusion in P. F. (Paul Frazer) Williams Publications by an authorized administrator of DigitalCommons@University of Nebraska - Lincoln. 


\title{
Photodetachment as a Control Mechanism for Diffuse Discharge Switches
}

\author{
GERHARD SCHAEFER, SENIOR MEMBER, IEEE, P. F. WILLIAMS, MEMBER IEEE, KARL H. SCHOENBACH, \\ SENIOR MEMBER, IEEE, AND JOHN T. MOSELEY
}

\begin{abstract}
Photodetachment is considered as a control mechanism for diffuse discharge switches. Experiments have been performed on photodetachment of ions in the flowing afterglow of a dc glow discharge in oxygen. Experiments with different laser wavelengths and the dependence of the optogalvanic signal on the laser energy flux indicate that $\mathrm{O}^{-}$ is the dominant negative ion. For an energy flux of $35 \mathrm{~mJ} / \mathrm{cm}^{2}, 50$ percent of the $\mathrm{O}^{-}$ions can be photodetached.
\end{abstract}

Manuscript received January 10, 1983; revised June 23, 1983. This work was supported by the Air Force Office of Scientific Research.

G. Schaefer, P. F. Williams, and K. H. Schoenbach are with the Department of Electrical Engineering, Texas Tech University, Lubbock, TX 74909 .

J. T. Moseley is with the Department of Physics and Chemical Physics Institute, University of Oregon, Eugene, OR 97403.

\section{INTRODUCTION}

RECEnTly, externally controlled diffuse discharge openRing switches have been considered for applications in inductive energy storage systems [1]. The discharges have to fulfill the requirement of low resistance during the conduction phase and high resistance during the opening phase. For fast opening times, which, in general, require rapid depletion of the electron density, the discharge has to be attachment-dominated in the opening phase. In optically controlled diffuse discharges the influence of the light can either be to enhance or to decrease the conductivity. For processes that increase the conductivity, the opening effect is achieved when the laseris turned 


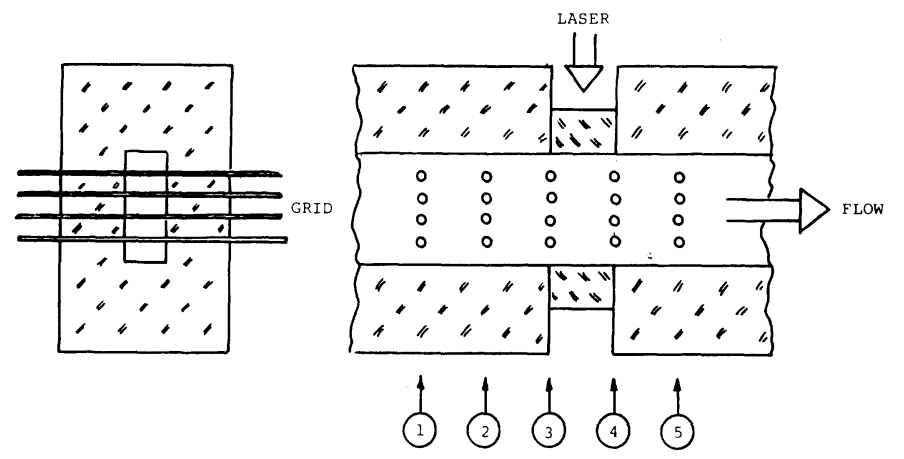

Fig. 1. Experimental setup for photodetachment experiments. Although only four are shown for clarity, ten parallel wires were used for each grid, as discussed in the text.

off. Photodetachment has been considered as a conductivityenhancing process [2]. Using photodetachment, a strong change of the conductivity of the discharge should be possible, if without photodetachment the negative ion density is much larger than the electron density, and if the electrons of the existing negative ions can be mostly detached by means of photodetachment.

To investigate the feasibility of photodetachment for optically controlled diffuse discharge switches we chose the negative ion $\mathrm{O}^{-}$for several reasons.

1. The photodetachment cross section of $\mathrm{O}^{-}, \sigma_{p . d}$., is well matched to our Nd:YAG-based laser system, in that $\sigma_{p . d}$. has a threshold at a photon energy of $h \nu=1.47 \mathrm{eV}$ and reaches a plateau at a photon energy of $2 \mathrm{eV}$. Thus the $1.06 \mu \mathrm{m}(1.17$ $\mathrm{eV}$ ) fundamental of the laser should produce no photodetachment of $\mathrm{O}^{-}$, whereas visible radiation, such as is obtained by frequency doubling or by pumping a dye laser, should produce strong photodetachment.

2. $\mathrm{O}^{-}$can easily be produced in discharges containing $\mathrm{O}_{2}$, $\mathrm{SO}_{2}, \mathrm{~N}_{2} \mathrm{O}$, or other oxides.

3. From $\mathrm{O}_{2}$ glow discharges it is well known that the negative ion density $N_{-}$can be much larger than the electron density $N_{e}[4]$.

\section{EXPERIMENTAL SETUP}

The experimental setup for our experiment is shown in Fig. 1. The flow tube has a rectangular cross section with dimensions $3 \times 14 \mathrm{~mm}^{2}$. Five grids, separated from each other by $2 \mathrm{~mm}$, are placed perpendicular to the flow axis. Each grid is made of 10 individual $\mathrm{Pt}$ wires with $0.127-\mathrm{mm}$ diameters. For photodetachment experiments in the flowing afterglow, a discharge was operated between grid 1 (cathode) and grid 2 (anode), with each wire of the cathode grid separately ballasted for discharge homogeneity. The region between grid 2 and grid 3 was generally kept nearly field-free, although for discharges with small admixtures of $\mathrm{O}_{2}$, a small negative voltage was applied to grid 3 to achieve zero current through grid 3 in dc operation. Between 3 and 4 a voltage of $5-100 \mathrm{~V}$ was applied to collect the photodetached electrons. The optogalvanic signal was detected by measuring the voltage across a resistor of between $1 \mathrm{k} \Omega$ and $1 \mathrm{M} \Omega$ in series with grid 3 . The fifth grid did not play an important role in the experiments described here, but was available to establish an exit condition for charged
TABLE I

Important Processes in $\mathrm{O}_{2}$ Discharges

\begin{tabular}{|c|c|}
\hline Reaction & $\begin{array}{l}\text { Charged } \\
\text { Product }\end{array}$ \\
\hline$\underset{\underline{E}}{\stackrel{\vec{\omega}}{E}(1)} \mathrm{e}+\mathrm{O}_{2}+0^{-}+0$ & $0^{-}$ \\
\hline 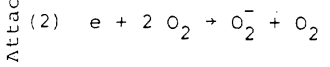 & $\mathrm{O}_{2}^{-}$ \\
\hline
\end{tabular}

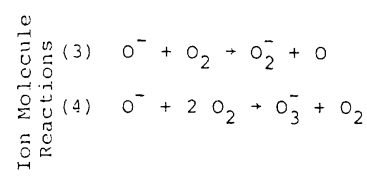

$\mathrm{O}_{2}^{-}$

$\mathrm{O}_{3}^{-}$

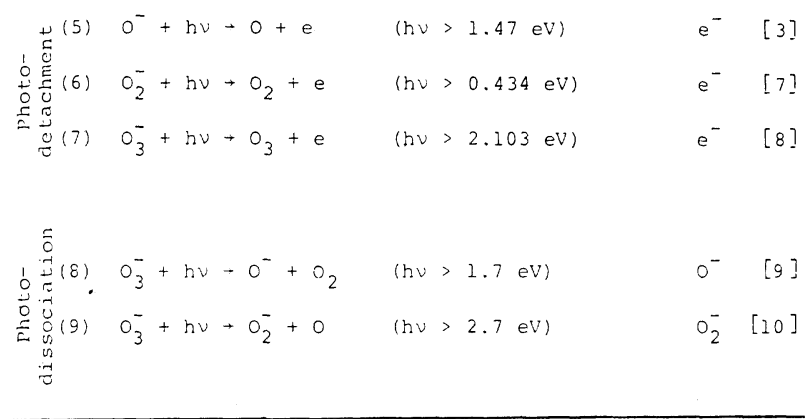

species passing through grid 4. Also, by establishing a discharge between grids 2 and 5, photodetachment effects within the discharge could be monitored using grids 3 and 4 . The light source was a Quanta-Ray PDL dye laser pumped by the Qswitched, frequency-doubled output of a Quanta-Ray DCR-1, $\mathrm{Nd}$ :YAG laser. The dye laser delivered pulses of about $50 \mathrm{~mJ}$ energy in $7 \mathrm{~ns}$.

\section{EXPERIMENTAL Results}

In a discharge containing $\mathrm{O}_{2}$, several different attachment processes and subsequent ion-molecule reactions are possible. For these, the important ions are $\mathrm{O}^{-}, \mathrm{O}_{2}^{-}$, and $\mathrm{O}_{3}^{-}$, and the processes with large reaction rates are shown in Table I. The dominant attachment process in the range $\left(E / p \leqslant 2 \mathrm{~V} \cdot \mathrm{cm}^{-1}\right.$. torr $^{-1}$ ) is the three-body attachment (reaction 2), while for higher values $\left(E / p \geqslant 2 \mathrm{~V} \cdot \mathrm{cm}^{-1} \cdot \operatorname{torr}^{-1}\right)$, the dissociative attachment (reaction 1) dominated [5]. Among the ion-molecule reactions, reaction (3), which produces $\mathrm{O}_{2}^{-}$, is important at higher values of $E / p$, while reaction (4), which produces $\mathrm{O}_{3}^{-}$, dominates at lower $E / p$ values [6]. The important photoinduced processes for these ions are also given in Table I. Of these, the Nd:YAG fundamental ouput with a photon energy of $1.17 \mathrm{eV}$ can induce only reaction (6).

In our experiment, the ions can either be produced in the discharge itself, where the value of $E / p$ varies in the range of $5 \leqslant E / p \leqslant 27 \mathrm{~V} \cdot \mathrm{cm}^{-1} \cdot$ torr $^{-1}$ (as determined by the discharge conditions), or in the nearly field-free drift region between grid 2 and 3 . To learn which ions are the dominant species under various discharge conditions, we performed optogalvanic experiments using either visible light $(h \nu \approx 2.2 \mathrm{eV})$ from the dye laser, or the $\mathrm{Nd}$ : YAG fundamental at $1.17 \mathrm{eV}$.

Some experimental results are shown in Table II. They indicate that for the range of discharge conditions we investigated, $\mathrm{O}_{2}^{-}$is produced best in pure $\mathrm{O}_{2}$ discharges at pres- 
TABLE II

Optogalvanic Signal for Different Discharge Conditions and Pump

FREQUENCIES

\begin{tabular}{|c|c|c|c|}
\hline 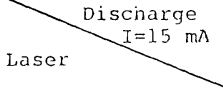 & $\begin{array}{l}\mathrm{p}=10 \text { torr } \\
\text { IIe }: \mathrm{O}_{2}=20: 1\end{array}$ & $\begin{array}{c}\mathrm{p}=0.3-0.8 \text { torr } \\
\mathrm{O}_{2} \text { only }\end{array}$ & $\begin{array}{c}\mathrm{p}=3-10 \text { torr. } \\
\mathrm{O}_{2} \text { only }\end{array}$ \\
\hline $\begin{array}{l}\text { Dye Laser } \\
560 \mathrm{~nm} \quad 10 \mathrm{~mJ}\end{array}$ & strong OGS & medium OGS & medium OGS \\
\hline $\begin{array}{l}\mathrm{Nd}-Y \Lambda \mathrm{G} \text { Laser } \\
1060 \mathrm{~nm} \quad 100 \mathrm{~mJ}\end{array}$ & weak OGS & weak OGS & medium OGS \\
\hline
\end{tabular}

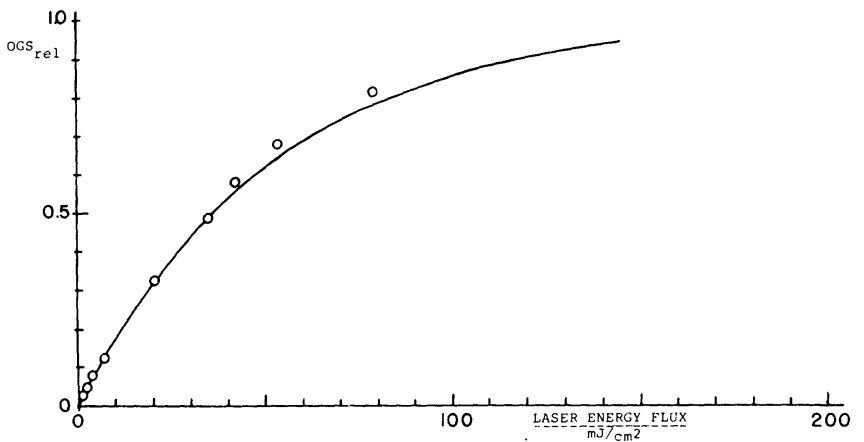

Fig. 2. Relative optogalvanic signal depending on laser energy flux. Discharge current was $1.5 \mathrm{~mA}$ in $10: 3 \mathrm{He}: \mathrm{O}_{2}$ mixture at 10 torr.

sures above 3 torr. We found that $\mathrm{O}_{2}^{-}$production was not a strong function of the voltage across the drift region (between grid 2 and 3), indicating that the attachment processes occur mainly in the discharge. Since the $E / p$ values for all discharge conditions are such that reaction (1) strongly dominates, we conclude that the production of $\mathrm{O}_{2}^{-}$at $\mathrm{O}_{2}$ pressures above 3 torr results from reaction (3) in the discharge. Consistent with our experimental observation this reaction should preferably occur at $E / p$ values above $10 \mathrm{~V} \cdot \mathrm{cm}^{-1} \cdot$ torr $^{-1}$ [6] and at the highest $\mathrm{O}_{2}$ pressures.

To distinguish between optogalvanic signals caused by $\mathrm{O}^{-}$ and $\mathrm{O}_{3}^{-}$we note that for $\lambda v>2 \mathrm{eV}$ photodissocitation (reactions (8) and (9) ) has been found to be the dominant photo process in $0_{3}^{-}[8]$. Of these, only reaction (8) is possible with the photon energies produced by our dye laser source $(h \nu \approx 2.2 \mathrm{eV})$. The cross section for reaction (8) has a spectral structure [9] which we did not observe in our experiments when the laser was tuned through the range $2.18-2.28 \mathrm{eV}$. We therefore conclude that the dominant optical electron generation mechanism in our experiment is direct photodetachment of $\mathrm{O}^{-}$.

To investigate whether the existing negative ions can be completely detached we performed saturation experiments in which the dependence of the optogalvanic signal strength on laser energy flux was determined. These results are shown in Fig. 2. The solid line shows the calculated result, assuming a photodetachment cross section of $\sigma=6.5 \times 10^{-18} \mathrm{~cm}^{2}$, and the circles indicate the result of our measurement. Since the optogalvanic signal is only measured in arbitrary units, the scale of the experimental curve was adjusted so that the slopes of the two curves agreed in the linear region $\left(<10 \mathrm{~mJ} / \mathrm{cm}^{2}\right)$. These results indicate that only $35 \mathrm{~mJ} / \mathrm{cm}^{2}$ of light energy flux is needed to photodetach 50 percent of the $\mathrm{O}^{-}$ions.

\section{CONCLUSION}

Our experiments demonstrate that photodetachment may be an attractive control mechanism for optically controlled diffuse discharge switches in systems where the negative ion density is much larger than the electron density. Assuming a time constant for attachment $t_{a} \approx 10^{-8} \mathrm{~s}$, for a gas mixture in a discharge producing $\mathrm{O}^{-}$, a power of $3.5 \mathrm{MW} / \mathrm{cm}^{2}$ is necessary to reduce the steady-state negative ion density by a factor of 0.5 . Work is continuing to determine the optogalvanic response of the discharge to photodetachment.

\section{ACKNOWLEDGMENT}

The authors are grateful to A. V. Phelps for very helpful discussions.

\section{REFERENCES}

[1] K. Schoenbach and M. Kristiansen, Eds., in Proc. ARO Wordshop on Diffuse Discharge Opening Switches, Tamarron, CO, Jan. 1982.

[2] K. H. Schoenbach, G. Schaefer, M. Kristiansen, L. L. Hatfield, and A. H. Guenther, "Concepts for optical control of diffuse discharge opening switches," IEEE Trans. Plasma Sci., vol. PS-10, pp. 246-251, Dec. 1982

[3] L. M. Branscomb, S. J. Smith, and G. Tisone, "Oxygen metastable atom production through photodetachment," J. Chem. Phys. vol. 43 , p. $2906,1965$.

[4] H. Sabadil, "Experimentelle Untersuchungen an wanderuden Niederfelddomaenen (T-Schichten) in der positiven Saeule von Gleichstrom und HF-Entladungen in Sauerstaff und SauerstoffStickstoff-Gemischen," Beitr. Plasma Phys., vol. 11, pp. 53 and $327,1971$.

[5] L. M. Chanin, A. V. Phelps, and M. A. Biondi, "Measurements of the attachment of low-energy electrons to oxygen molecules," Phys. Rev., vol. 128, p. 219, 1962.

[6] J. L. Moruzzi and A. V. Phelps, "Survey of negative-ion-molecule reactions in $\mathrm{O}_{2}, \mathrm{CO}_{2}, \mathrm{H}_{2} \mathrm{O}$, and mixtures of these gases at high pressures," J. Chem. Phys., vol. 45, p. 4617, 1966.

[7] D. S. Burch, S. J. Smith, and L. M. Branscomb, "Photodetachment of $\mathrm{O}_{2}^{-}$," J. Chem. Phys., vol. 112, p. 171, 1958.

[8] P. C. Cosby, J. T. Moseley, J. R. Peterson, and J. H. Ling, "Photodissociation spectroscopy of $\mathrm{O}_{3}^{-}$,"J. Chem. Phys., vol. 69, p. 2771, 1978.

[9] P. C. Cosby, R. A. Bennett, J. R. Peterson, and J. T. Moseley, "Photodissociation and photodetachment of molecular negative ions. II. Ions formed in oxygen," J. Chem. Phys., vol. 63, p. $1612,1975$.

[10] L. C. Lee and G. P. Smith, "Photodissociation and photodetachment of molecular negative ions. VI. Ions in $\mathrm{O}_{2} / \mathrm{DH}_{4} / \mathrm{H}_{2} \mathrm{O}$ mixtures from 3500 to 8600 A," J. Chem. Phys., vol. 70, p. 1727 , 1979.

[11] G. Schaefer, P. F. Williams, K. H. Schoenbach, and J. T. Moseley, "Photodetachment as a control mechanism for diffuse discharge switches," in Proc. 35th G.E.C., p. EA-5, 1982. 